\title{
Energetically Optimal Cadence vs. Freely-Chosen Cadence During Cycling: Effect of Exercise Duration
}

\author{
J. Brisswalter ${ }^{1}$, C. Hausswirth ${ }^{2}$, D. Smith ${ }^{3}$, F. Vercruyssen ${ }^{4}$, J. M. Vallier ${ }^{5}$ \\ 'Université de Toulon-Var, France \\ ${ }^{2}$ Laboratoire de Physiologie et Biomécanique. INSEP, Paris, France \\ ${ }^{3}$ Queensland Academy of Sport Triathlon, Brisbane, Australia \\ "LAPMH, Université de Poitiers, France \\ 5service Médical, INSEP, Paris, France
}

Publié dans : Int J Sports Med 2000; $21(1)$ : 60-64

Brisswalter J. Hausswirth C, Smith D, Vercruyssen F, Vallier JM. Energetically Optimal Caclence vs. lireely-Chosen Cadence During Cycling: Elfect of Exercise Duration. Int ] Sports Med 1999; 20: $60-64$

Accepted after revision: July 19, 1999

\begin{abstract}
The purpose of this study was to examine the relationship between cadence and oxygen consumption with exercise duration. Ten triathletes who trained regularly were examined. The first test was always a maximal test to determine maximal oxygen uptake $\left(\mathrm{VO}_{2} \mathrm{max}\right)$. The other sessions were composed of six submaximal tests representing $80 \%$ of the maximal power reached with $\mathrm{VO}_{2} \max \left(\mathrm{P}_{\mathrm{max}}\right)$. During these tests submaximal rides with a duration of $30 \mathrm{~min}$ were performed. Each test represented, in a randomised order, one of the following pedal rates: $50,65,80,95,110 \mathrm{rpm}$ and a freely-chosen rate. $\mathrm{VO}_{2}$, respiratory parameters, and heart rate were monitored continuously. Two periods, between the 3rd and the 6th minute and between the 25 th and the 28th minute, were analysed. Results showed that when $\mathrm{VO}_{2}$ and heart rate were plotted against cadence, each curve could be best described by a parabolic function, whatever the period. Furthermore, a significant effect of period was found on energetically optimal cadence $(70 \pm 4.5$ vs. $86 \pm 6.2 \mathrm{rpm}$, $P<0.05)$. Only during the second period was no significant difference found between freely-chosen cadence $(83 \pm 6.9 \mathrm{rpm}$ ) and energetically optimal cadence $(P>0.05)$. In conclusion, our results suggest that during prolonged exercise triathletes choose a cadence that is close to the energetically optimal cadence. A change of muscle fibre recruitment pattern with exercise duration and cadence would explain the shift in energetically optimal rate towards a higher pedal rate observed at the end of exercise.
\end{abstract}

Key words: Cadence, locomotion, oxygen uptake, fatigue.

Int J Sports Med 2000; 21: 60-64

(1) Georg Thieme Verlag Stuttgart - New York ISSN $0172-4622$

\section{Introduction}

In long distance events (e.g. triathlon, marathon, race waiking...) the maximal speed that athetes can sustain depends on the capacity of the subject to support the highest fraction of $\mathrm{VO}_{2} \max$ and to spend the lowest amount of metabolic energy during the whole race [14]. In this case the energy cost of locomotion, defined as the amount of energy spent per unit distance, contributes significantly to long duration performance $[4,7,13,32,37\}$. It is well-known that the energy cost of locomotion also reflects the biomechanical demand associated with changes in movement pattern $[17,41]$. Therefore in order to minimise the energy cost of locomotion, the choice of a particular cadence in cycling or running is classically evoked by coaches and researchers. For running or walking the relationship between movement frequencies and energy cost has been widely studied, often suggesting that the performer spontaneously adopts the pattern of locomotion leading to the lowest energy cost $[6,23,24]$. This does not appear to be the case for cycling. On the one hand the energetically optimal cadence ranges from $40 \mathrm{rpm}$ to $80 \mathrm{rpm}$ in trained or untrained cyclists $[10,11,16,17]$, but on the other hand observations of cyclists often reveal that the freely chosen cadence is significantly higher than the most economical cadence (e.g., [17]). The following functional assumptions have been made to explain this apparent conflict: changes in pedalling forces [34], neuromuscular activation [30], or variation in ventilatory parameters $\{20 \mid$. However, results remain inconsistent, thus highlighting the difficulty in identifying factors that affect the relationship between energy cost and cadence $[15,28,29]$. In fact optimisation principles governing locomotion for cycling are probably as numerous as for other forms of locomotion, and thus the adoption of a specific locomotor pattern could be seen as a function of a) the task constraints and b) the constraints of the performer $[25,31\}$.

The main constraint occurring during long distance events is the exercise duration. Previous studies conducted on marathon runners [7], racewalkers [4], and triathletes [18,21,22. 26] have observed a significant increase in energy cost of locomotion with exercise duration leading to the acloption of a specific pattern of locomotion during fatigue $[4,22]$. A number of mechanisms have been hypothesized to account for this increase in energy cost. During moderate to high intensity exercise the hypothesis that $\mathrm{VO}_{2}$ rise during prolonged exercise is related to the recruitiment of type Il muscle fibres is often sug- 
Table 1 Characteristics of the subjects

\begin{tabular}{|c|c|c|c|c|c|c|c|}
\hline $\begin{array}{l}\text { Age } \\
\text { (years) }\end{array}$ & $\begin{array}{l}\text { mass } \\
(\mathrm{kg})\end{array}$ & $\begin{array}{l}\text { height } \\
\text { (cm) }\end{array}$ & $\begin{array}{l}\dot{\mathrm{VO}} \mathrm{O}_{2} \max \\
\left(\mathrm{ml} \times \mathrm{kg}^{-1} \times \mathrm{min}^{-1}\right)\end{array}$ & $\begin{array}{l}H R_{\max } \\
\text { (bpm) }\end{array}$ & $\begin{array}{l}P_{\max } \\
\text { (watts) }\end{array}$ & $\begin{array}{l}\mathrm{LA}_{\mathrm{max}} \\
\left(\mathrm{mmol} \times L^{-1}\right)\end{array}$ & $R E R_{\max }$ \\
\hline $26 \pm 2$ & $67.5 \pm 3$ & $178 \pm 3.3$ & $66.4 \pm 3.4$ & $187.3 \pm 6$ & $376.5 \pm 20$ & $15.8 \pm 2.3$ & $1.21 \pm 0.03$ \\
\hline
\end{tabular}

gested $[18,35]$. Moreover, during cycling a preferential recruitment of type II fibres seems to occur at low $(<50 \mathrm{rmp})$ and at high pedal rates $(<100 \mathrm{rmp}$ ) [36]. These observations raise two questions, one concerning the effect of fatigue on the choice of a particular cycling cadence and the other concerning the consequences of this choice on the energy cost increase with exercise duration. The principal purpose of this study was therefore to investigate whether the relationship between energetically optimal and freely-chosen cadence was affected by prolonged endurance exercise. A second objective was to examine the effect of pedal rate on $\mathrm{VO}_{2}$ rise (i.e. energy cost increase) during constant intensity prolonged cycling.

\section{Materials and Methods}

Subjects

The subjects were ten triathletes in regular training. The physical characteristics of the subjects are given in Table $\mathbf{1}$. Before participating in this study, subjects were fully informed about protocol, and informed consent was obtained prior to all testing.

\section{Experimental design}

Each subject completed 7 testing sessions during a 3 week period without any other training program. Each session was separated by a $48 \mathrm{~h}$ rest period. An electromagnetically braked ergometer, equipped with the triathlete's own pedals and toeclips and adjusted to the dimensions of their own bicycle, was used during all testing. The first session, performed at freelychosen cadence, was used to accustom subjects to the laboratory and to determine $\mathrm{VO}_{2} \max \left(\mathrm{ml} \times \min ^{-1} \times \mathrm{kg}^{-1}\right)$. After $6 \mathrm{~min}$ at $100 \mathrm{~W}$ the power output was increased by $25 \mathrm{~W}$ each minute until exhaustion. $\mathrm{VO}_{2}$ max was attained with a plateau in $\dot{\mathrm{VO}}_{2}$, an expiratory ratio of 1.15 or greater and a post blood lactate level above $8 \mathrm{mmol} \times \mathrm{I}^{-1}$. The other sessions were composed of a 6 min control ride followed by a 30 min submaximal test, at $80 \%$ of the maximal power reached with $\dot{\mathrm{VO}}_{2} \max$ $\left(\mathrm{P}_{\max }\right)$. For each test, after the control ride caused out at the preferred cadence, one of the following pedal rates 50,65, 80, $95,110 \mathrm{rpm}$ or a freely-chosen rate was presented in a random order. Cadence, $\mathrm{VO}_{2}$, respiratory parameters (VE, RF, RER), and heart rate (HR) were monitored continuously. Lactate was measured by enzymatic method (Yellow Springs Instruments Model 24L) from a finger blood sample taken at rest and immediately at the end of the exercise. Two periods, between the 3 rd -6 th and the 25 th -28 th min, were analysed.

\section{Statistical analysis}

All data are expressed as mean \pm SD. Short term variability between trial tests was analysed, first using repeated measures ANOVA on $\dot{\mathrm{VO}}_{2}$, respiratory parameters, heart rate, and cadence recorded during the control rides. Coefficients of varia- tion $(S D /$ mean $\times 100)$ were then calculated for each subject $[3,5]$. Based on previous studies, the relation between cadence and $\mathrm{VO}_{2}$ for each subject was fitted using a polynomial regression with a quadratic model $[10,11,28,29]$. The minimum point of the curve represented the energetically optinal cadence. Firstly a 2-way MANOVA (period $x$ cadence) was performed using $\mathrm{VO}_{2}$ respiratory parameters and heart rate as dependant variables (Statistica ver. 5). A one-way ANOVA was performed to analyse the effect of cadence on lactate values recorded at the end of each test. For all analyses Newman-Keuls post hoc test was employed to determine differences among pedal rates. A paired t-test was used to test differences in freely-chosen cadence between the two periods and differences between the energetically optimal and freely-chosen cadence. For all the statistical analyses the level of significance was set at $\mathrm{P}<0.05$.

\section{Results}

\section{Maximal test}

The maximal values obtained during the first session are presented in Table 1 . The RER values and peak post-exercise blood lactate levels $\left(\mathrm{LA}_{\max }\right)$ indicate the achievement of $\dot{\mathrm{VO}}_{2}$ criteria and permitted using a $P_{\max }$ value.

\section{Submaximal test}

No significant difference in $\dot{\mathrm{V}} \mathrm{O}_{2}$ was found. The mean coefficient of variation for $\dot{\mathrm{VO}}_{2}$ was $2.8 \pm 0.4 \%(\mathrm{P}>0.05)$. Furthermore, the coefficient of variation of freely-chosen cadence was small for all subjects (mean $=1.8$; range : $1.5-2.3$ ) indicating that the preferred cadence of these triathletes was stable at $80 \% \mathrm{P}_{\max }$

Data on cardio-respiratory responses at different pedal rates are presented in Table 2 . Analysis of variance showed that $\mathrm{VO}_{2}$ and heart rate were different among pedal rates whatever the period. When $\mathrm{VO}_{2}$ was plotted against pedal rate using a quadratic model, mean values of regression coefficients for $\mathrm{VO}_{2}$ during the first and the second period were $r=0.90$ (range 0.87 0.96 ) and $r=0.98$ (range $=0.96-0.99$ ) respectively (Fig. 1 )

A significant effect of period was found for $\dot{\mathrm{VO}}_{2}$ and for energetically optimal cadence. The lowest point of the graph was found for the first and the second period at $70 \pm 4.5$ and $86 \pm 6.2 \mathrm{rpm}$, respectively $(\mathrm{P}<0.05)$. A significant increase in oxygen uptake was observed with exercise duration for all pedal rates except for $95 \mathrm{rpm}(\mathrm{P}>0.05)$. The most important rise in $\dot{\mathrm{VO}}_{2}\left(\Delta \dot{\mathrm{VO}}_{2}=\dot{\mathrm{VO}}_{2}\right.$ period $2-\dot{\mathrm{VO}}_{2}$ period 1$)$ was found at $110 \mathrm{rpm}\left(\Delta \dot{V O}_{2}=4.9+0.33 \mathrm{ml} \times \mathrm{kg}^{-1} \times \mathrm{min}^{-1}\right)$ while at $95 \mathrm{rpm}$ $\Delta \dot{V O O}_{2}$ was equal to $1.9+0.42 \mathrm{ml} \times \mathrm{kg}^{-1} \times \mathrm{min}^{-1}$ (Fig. 2). Furthermore, for the second period blood lactate levels and VE values were significantly higher at $110 \mathrm{rpm}$ than at the other pedal rates $(\mathrm{P}<0.05$, Fig. 3 ). 
Table 2 Mean oxygen uptake $\left(\mathrm{VO}_{2}\right)$, ventilation (VE), heart rate (HR), and lactate concentration $(L A)$ associated with the 5 controlled and the freely chosen (FC) cycling cadences

\begin{tabular}{|c|c|c|c|c|c|c|c|}
\hline Cadences $\left(\right.$ rev $\left.\times \min ^{-1}\right)$ & & 50 & 60 & 80 & 95 & 110 & $\mathrm{FC}$ \\
\hline \multirow[t]{2}{*}{$\dot{\mathrm{V}} \mathrm{O}_{2}\left(\mathrm{ml} 1 \times \mathrm{kg}^{-1} \times \mathrm{min}^{-1}\right)$} & Period 1 & $53.1 \pm 3$ & $50.2 \pm 4.5^{b}$ & $49.8 \pm 4.5$ & $52.1 \pm 3.7^{b}$ & $52.8 \pm 4.2$ & $50.4 \pm 4.5$ \\
\hline & Period 2 & $56.8 \pm 4^{a}$ & $55.4 \pm 4.7^{a}$ & $53.8 \pm 4^{\mathrm{ab}}$ & $54.1 \pm 5.1$ & $57.6 \pm 4.2^{\mathrm{ab}}$ & $53.9 \pm 4.1^{3}$ \\
\hline \multirow[t]{2}{*}{ VE $\left(i \times \min ^{-1}\right)$} & Period 1 & $92.4 \pm 10$ & $92.2 \pm 9$ & $89.1 \pm 8$ & $89.8 \pm 11$ & $102 \pm 15^{b}$ & $89.2 \pm 9$ \\
\hline & Period 2 & $111.2 \pm 9^{\mathrm{a}}$ & $106.8 \pm 13^{a}$ & $104.4 \pm 11^{\mathrm{a}}$ & $106.4 \pm 11^{\mathrm{a}}$ & $128.9 \pm 18^{\mathrm{ab}}$ & $107.6 \pm 13^{\mathrm{a}}$ \\
\hline \multirow[t]{2}{*}{ HR (bpm) } & Period 1 & $162 \pm 15$ & $156 \pm 11^{b}$ & $157 \pm 16$ & $160 \pm 14$ & $167 \pm 16^{b}$ & $158 \pm 11$ \\
\hline & Period 2 & $172 \pm 11^{a}$ & $170 \pm 13^{3}$ & $166 \pm 13^{\mathrm{ab}}$ & $168 \pm 12^{\mathrm{a}}$ & $175 \pm 14^{\text {ab }}$ & $168 \pm 13$ \\
\hline $\mathrm{LA}\left(\mathrm{mmol} \times \mathrm{L}^{-1}\right)$ & & $3.5 \pm 0.8$ & $3.4 \pm 1.2$ & $3.7 \pm 0.6$ & $4.1 \pm 1.1$ & $5.8 \pm 2.3^{b}$ & $3.6 \pm 0.9$ \\
\hline
\end{tabular}

a represents significant difference between the two periods

b represents significant differences with the previous controlled cadence (from Newman-Keuls post hoc test, $\mathrm{p}<.05$ )

$\mathrm{VO}_{2} \mathrm{ml} \cdot \mathrm{kg}^{-1} \cdot \mathrm{min}^{-1}$

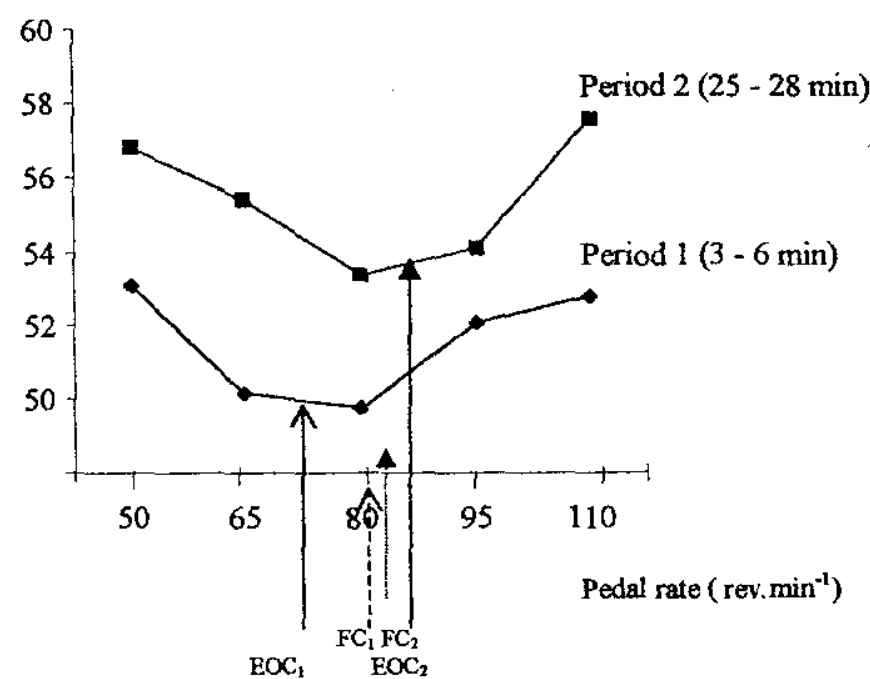

Fig. 1 Group mean responses for steady $\mathrm{VO}_{2}$ as a function of pedal rate before and after a $30 \mathrm{~min}$ cycling exercise.

$\rightarrow E O C_{1}$ : mean energetically optimal cadence during the first period, $\rightarrow \mathrm{EOC}_{2}$ : mean enegetically optimal cadence during the second period, $\rightarrow \mathrm{FC}_{\mathrm{T}}$ : mean freely-cosen cadence during the first period,

$\rightarrow \mathrm{FC}_{2}$ : mean freely-chosen cadence during the second period.

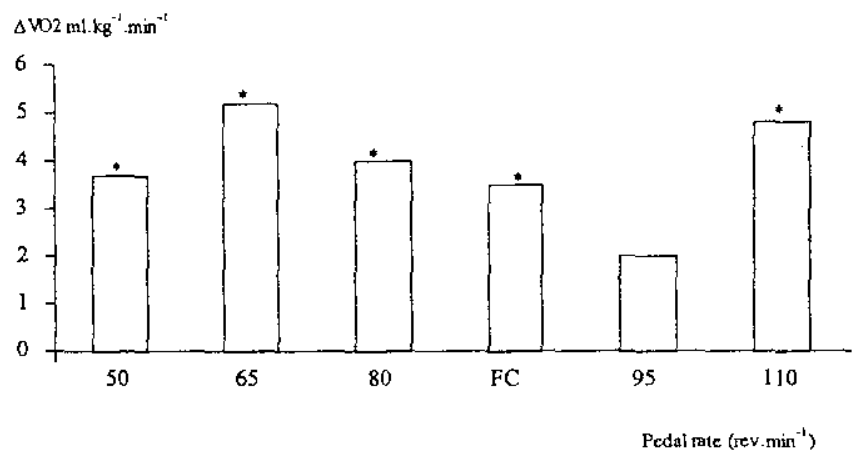

Fig. 2 Group mean responses for $\Delta \dot{V O O}_{2}\left(\dot{V O O}_{2}\right.$ period $2-\dot{\mathrm{VO}} 2$ period 1) as a function of pedal rate.

* significant difference between the two periods ( $p<0.05$, FC represents the freely-chosen cadence (respective values for the first and the second period: $80 \pm 7.1$ vs. $83 \pm 6.9 \mathrm{rpm}$ ).

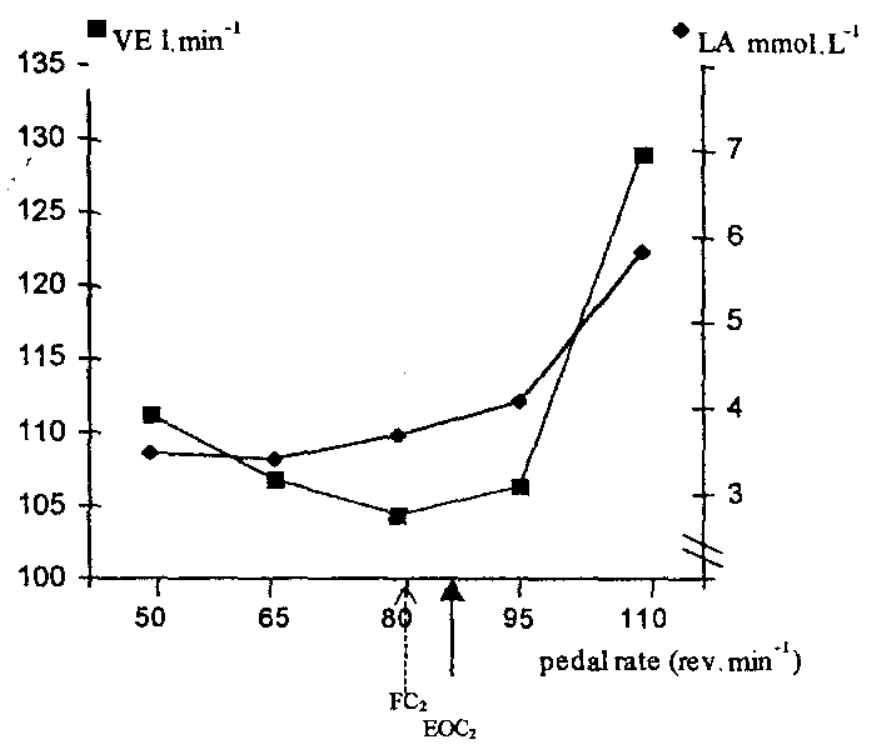

Fig. 3 Group mean responses for steady state ventilation (VE) and post exercise lactate concentration (LA) as a function of pedal rate during the second period of cycling exercise.

$\rightarrow \mathrm{EOC}_{2}$ : energetically optimal cadence during the second period

$\rightarrow \mathrm{FC}_{2}$ : the freely-chosen cadence during the second period.

No significant difference in freely-chosen cadence was found between the first and the second period $(80 \pm 7.1$ vs. $83 \pm 6.9 \mathrm{rpm}$, respectively). Moreover, only during the second period did the freely-chosen cadence not differ significantly from the energetically optimal cadence $(P>0.05)$.

\section{Discussion}

The results clearly show the existence of an energetically optimal pedalling rate for a constant power output close to competition pace in trained triathletes independent of the duration of exercise. Nevertheless, the most significant finding of this investigation was the statistically significant shift of the energetically optimal cadence over exercise duration towards a higher pedal rate which is closer to the athletes freely-chosen cadence.

However, the comparison with previous findings must take into account the possible effect of several factors. On the one 
hand, the validity of the measure of energy cost of the cycling task from $\mathrm{VO}_{2}$ values and the use of heart rate as an indicator of intensity level depends on the assumption that exercise was strictly aerobic [14]. In our study carried out on triathletes, during the second period the $110 \mathrm{rpm}$ pedal rate appears to be a partial anaerobic exercise. Mean blood lactate concentration and respiratory exchanges ratio values were $5.8 \mathrm{mmol} \times \mathrm{L}^{-1}$ and 1.15 respectively, and for this pedal rate the above assumption appears to be violated (Table 2 ). On the other hand, comparison of cadence effects depends on the short term reproducibility of physiological variables between sessions. No statistical variability in physiological parameters or freelychosen cadence was found in this study $(P>0.05)$. This result concurs with previous studies and indicates the reproducibility of energy cost measurement in trained subjects $[3,5]$.

To the best of our knowledge the effect of exercise of a duration longer than 6 minutes on the cycling economy cadence relation has not been well studied. Furthermore, although a lot of research has been conducted with trained cyclists, similar studies with triathletes are not available [32]. For short-term exercise the physiologically optimal cadences observed in our first period were within the range classically reported in the experimental literature for this power output in trained cyclists (e.g. [17]). For a longer period of work, since Coast et al. [11] found no difference in optimal pedal rate during a $20 \mathrm{~min}$ ride in five cyclists, the present resuits suggest that after the 20th minute a shift of this optimal rate could occur in a homogeneous group of triathletes. The differentiated effect of exercise duration on optimal cadence between cyclists and triathletes could be partly related to an individual's cycling experience also affecting the choice of a preferred cadence. In general studies have indicated that experienced cyclists use pedalling frequencies higher than $90 \mathrm{rpm}$ whereas untrained cyclists prefer frequencies around $60 \mathrm{rpm}$. Cycling-experience as well as training or race specificity are thought to affect this adaptation (e.g. $[10,15,17]$ ). In this study the preferred pedalling rate of our triathletes at $80 \mathrm{rpm}$ suggests that this choice could be influenced by the specificity of training mode in triathlon [38]. Both volume and specificity of training in cycling (triathletes vs. cyclists) appears to be a discriminant factor of a freelychosen cadence and having an effect on the energetically optimal cadence [28]. Marsh and Martin [29] reported a training volume in cyclists of category II riding $402 \mathrm{~km} \times \mathrm{wk}^{-1}$ (250 miles $\times w^{-1}$ ), whereas Hausswirth et al. [22] reported a training volume of $155 \mathrm{~km} \times w^{-1}\left(96\right.$ miles $\left.\times w^{-1}\right)$ for a triathlete population specialised in Olympic distance. Moreover, in contrast to a cycle race, during the cycling section of a triathlon race the triathletes would generally try to minimise their energy demand in anticipation of the subsequent running section. This finding suggests that in trained triathletes the most economical pedalling rate could be coincident with the pedalling rate most preferred in prolonged ( $>20 \mathrm{~min}$ ) exercise of moderate-high intensity. However, further comparative studies between cyclists and triathletes are needed to test this hypothesis.

The relationship between energetically optimal and freelychosen cadences remain unclear, and several studies have suggested that minimisation of aerobic demand is not a key determinant of preferred cadence selection $[28,29,34,40]$. Recent studies have reported that the preferred pedalling rate of experienced cyclists was coincident with a minimisation of neu- romuscular fatigue and not with a minimisation of aerobic de mand $[30,39,40]$. At the beginning of exercise our data provide support for this hypothesis. During the first period the preferred pedal rate $(80+7.1 \mathrm{rpm})$ was significantly higher than the energetically optimal cadence $(70+4.5 \mathrm{rpm}, \mathrm{P}<0.05)$. However, during the test no significant effect of fatigue was observed on preferred pedal rate, and a shift of the energetically optimat cadence towards the preferred pedal rate was reported. Furthermore our study found a significant effect of cadence on $\mathrm{VO}_{2}$ rise during exercise. A possible explanation for these effects could be related to a change of working muscle activity pattern with exercise duration. Several studies have also suggested the important link between a change in motor unit recruitment and the additional increase in $\mathrm{VO}_{2}$ during prolonged moderate to high intensity exercise $[2,35]$. On the one hand, prolonged exercise is commoniy associated with changes in EMC activity pattern and/or changes in fibre recruitment. With exercise duration the use of type I fibres is followed by recruitment of type II fibres $[2,9,19,20,35]$. However, type II fibre has a lower muscle efficiency (i.e. higher energy phosphate produced per oxygen molecule consumed) than type I fibre $[10,42]$. Therefore the supplementation of type I by type II fibres during prolonged exercise would be related to a decrease in thermodynamical muscle efficiency leading to an increase in energy cost [42].

On the other hand, during prolonged exercise the effect of type II fibre recruitment on $\dot{V O}_{2}$ increase $\left(\Delta \dot{V O}_{2}\right)$ could be enhanced by manipulation of pedal rate. Within this framework Ahlquist et al. [1] demonstrated during a 30 min ride at $85 \%$ of maximal aerobic capacity that a $50 \mathrm{rpm}$ cyciing rate but not a $100 \mathrm{rpm}$ cadence is associated with an increase in the recruitment and glycogen depletion of type Il fibres. For cycling exercise at a constant force it is suggested that a preferential recruitment of the type Il fibres occurs at low pedal frequencies $(<50 \mathrm{rpm})$ and when concentration velocity is high $(>100 \mathrm{rpm})[36,39]$. Furthermore Takaishi et al. [40] indicated that the preferred pedalling rate of experienced cyclists (75-90 rpm) was related to a decrease in muscle stress and a preferential recruitment of type I fibres. Our results support indirectly the hypothesis of muscle fibre recruitment on $\Delta \mathrm{VO}_{2}$. In our study the lowest pre to post trial difference in $\Delta \mathrm{VO}_{2}$ was observed at $95 \mathrm{rpm}$ while the highest values of $\Delta \dot{V}_{2}$ were observed at 65 and $110 \mathrm{rpm}$ (Fig. 2). This differential effect of pedal rate on $\Delta \dot{V}_{2}$ may explain therefore the shift in energetically optimal cadence towards higher pedal rates at the end of the test.

In conclusion, during a $30 \mathrm{~min}$ ride performed at a habitual competition pace triathletes choose a cadence that is close to the energetically optimal cadence. Our results suggest that the change of working muscle activity pattern with exercise duration/and or pedal rate could be related firstly to the increase in $\mathrm{VO}_{2}$ with time and secondly to the shift in energetically optimal rate towards a higher cadence at the end of exercise.

\section{References}

${ }^{1}$ Ahiquist LE, Bassett DR Jr, Sufit R, Nagle FJ, Thomas DP. The effect of pedalling frequency on glycogen depletion rates in type I and type Il quadriceps muscle fibres during submaximal cycling exercise. Eur J Appl Physiol 1992; 65: 360-364 
2 Barstow TJ, jones AM, Nguyen PH, Casabury R. Influence of muscle fiber type and pedal frequency on oxygen uptake kinetics of heavy exercise. J Appl Physiol 1996; 81: 1642-1650

${ }^{3}$ Becque MD, Katch V. Marks C, Dyer R. Reliability and within subject variability of $\mathrm{VE}, \mathrm{VO}_{2}$, heart rate and blood pressure during submaximum cycle ergometry. Int J Sport Med 1993; 14: 220223

${ }^{4}$ Brisswalter J, Fougeron B, Legros P. Effect of three hours racewalk on energy cost and stride rate in elite racewalkers. Int J Sports Med 1996; 17: $182-186$

${ }^{5}$ Brisswalter J, Legros P. Daily stability in energy cost running, respiratory parameters and stride rate among well trained middle distance runners. Int J Sports Med 1994; 15: 238 - 241

${ }^{6}$ Brisswalter ], Mottet D. Energy cost and stride duration at preferred transition gait speed between walking and running. Can Appl Physiol 1996: 21: $471-480$

${ }^{7}$ Bruckner JC, Atchou G, Capelli C, Duvallet A, Joussellin E, Rieu M. The energy cost of running increase with distance covered. Eur J Appl Physiol 1990; 62: 68 - 72

${ }^{8}$ Clauser F. Effect of physiological training on cardiovascular adjustments to exercise in man. Physiol Rev 1977; 57: 774 - 815

${ }^{9}$ Citterio G, Sironi S, Piccoli S, Agostini E. Slow to fast shift in inspiratory muscle fibres during heat tachypnea. Respir Physiol $1983 ; 51 ; 259-274$

${ }^{10}$ Coast $\mathrm{J}$, Welch HG. Linear increase in optimal pedal rate with increased power output in cycle ergometry. Eur J Appl Physiol 1985; $53: 339-342$

${ }^{11}$ Coast JR, Cox RH, Welch HG. Optimal pedalling rate in prolonged bouts of cycle ergometry. Med Sci Sports Exerc 1986; 18: 225 230

${ }^{12}$ Coyle EF, Sdossis LS, Horowitz JF, Beltz JD. Cycling efficiency is related to percentage of type I muscle fibres. Med Sci Sports Exerc 1992; $24: 782-788$

${ }^{13}$ Dengel DR, Flynn MG, Costill DL. Determinants of success during triathlon competition. Res Q Exerc Sport 1989; 60: 234-238

${ }^{14}$ Di Prampero PE. The energy cost of human locomotion on land and in water. Int J Sports Med 1986; $7: 55-72$

${ }^{15}$ Faria IE. Energy expenditure, aerodynamics and medical problems in cycling. Sports Med 1992; 14: 43-63

${ }^{16}$ Gaesser GA, Brooks GA. Muscular efficiency during steady state exercise: effect of speed and work rate. J Appl Physiol 1975; 38: $1132-1139$

${ }^{17}$ Gregor RJ, Broker JP, Ryan MM. The biomechanics of cycling. Exercise and Science Review 1991; 9: 127-168

${ }^{18}$ Guezennec CY, Bigard AX, Vallier JM, Durey A. The energy cost of running increase at the end of a triathlon. Eur J Appl Physiol 1996: $73: 440-445$

${ }^{19}$ Gollnick PD, Piehl K, Saltin B. Selective glycogen depletion pattern in human muscle fibres after exercise of varying intensity and at varying pedal rates. J Physiol 1974; $214: 45-57$

${ }^{20}$ Hagan RD, Weiss SE, Raven PB. Effect of pedal rate on cardiorespiratory responses during continuous exercise. Med Sci Sports Exerc 1992; 24: 1088 - 1095

21 Hausswirth C, Bigard AX. Berthelot M, Thomaidis M, Guezennec CY. Variability in energy cost of running at the end of a triathlon and a marathon. Int J Sports Med 1996; 17: 574-581

${ }^{22}$ Hausswirth C, Bigard AX, Guezennec CY. Relationships between running mechanics and running efficiency at the end of a triathIon and a marathon. Int J Sport Med 1997; 18: 1 - 10

${ }^{23} \mathrm{Heglund}$ NC, Taylor CR. Speed, stride frequency and energy cost per stride: how do they change with body size and gait? J Exp Biology 1988: 138: $301-318$

24 Holt KG, Hamill J. Andres RO. Predicting the minimal energy cost of human walking. Med Sci Sports Exerc 1991; 25: $491-498$

${ }^{25}$ Kelso JAS, Scholtz JP, Schöner G. Dynamics governs switching among pattern of coordination in biological movement. Physical Letters A 1988; $134: 8-12$
${ }^{26}$ Kreider RB, Boone T, Thompson WR, Burke S, Cortes CW. Cardio vascular and thermal responses of triathion performance. Med Sci Sports Exerc 1988; 20: $385-390$

${ }^{27}$ Laurenson NM, Fulcher KY, Korkia P. Physiological characteristic of elite and club level female triathletes during running. Int Sports Med 1993; 14: 455 -459

${ }^{28}$ Marsh AP, Martin PE. Effect of cycling exercise, aerobic power, power output on preferred and most economical cycling cadences. Med Sci Sports Exerc 1997; 29: $1225-1232$

${ }^{29}$ Marsh AP, Martin PE. The association between cycling experience and preferred and most economical cadences. Med Sci Sports Exerc 1993: 25: 1269 - 1274

${ }^{30}$ Neptune RR. Hull ML. A theoretical analysis of preferred pedalling rate selection in endurance cycling. J Biomech 1999: 32: 409415

${ }^{31}$ Newell KM, Kugler PN, Emmerick R, Mc Donald PV. Search strategies in the acquisition of coordination. In: Wallace SA (ed). Perspectives on the coordination of movement. Amsterdam, North Holland: 1989: $85-122$

${ }^{32}$ O'Toole ML, Douglas PS. Applied Physiology of Triathlon. Sports Med 1995; 19: $251-267$

${ }^{33}$ O'Toole ML, Douglas PS, Hiller WDB. Lactate, oxygen uptake and cycling performance in triathletes. Int J Sports Med 1989; 10 $413-418$

34 Patterson RP, Moreno MI. Bicycle pedalling forces as a function of pedalling rate and power output. Med Sci Sports Exerc 1990; 22 $512-516$

${ }^{35}$ Poole DC, Richardson RS. Determinants of oxygen uptake: implications for exercise testing. Sports Med 1997; 24: $308-320$

${ }^{36}$ Sargeant AJ. Human power output-Determinants of maximum performance. In: Marconnet P, Saltin B, Komi P, Poortmans (eds). Human Muscular Function during Dynamic Exercise. Basel Karger, 1996: $10-20$

${ }^{37}$ Sleivert GG, Rowlands S. Physical and physiological factors associated with success in the triathlon. Sports Med 1996; 1: 8-18

${ }^{38}$ Tanaka H. Effects of cross-training: transfer to training effects on $\dot{\mathrm{V}}_{2}$ max between cycling, running and swimming. Sports Med 1994; 18: $330-339$

${ }^{39}$ Takaishi T, Yasuda TY, Ono T, Moritani T. Optimal pedalling rate estimated from neuromuscular fatigue for cyclists. Med Sci Sports Exerc 1996; 28: $1492-1497$

${ }^{40}$ Takaishi T, Yamamoto TY, Ono T. Ito T, Moritani T. Neuromuscular, metabolic and kinetic adaptations for skilled pedalling performance in cyclists. Med Sci Sports Exerc 1998; 30: 442 - 449

41 Williams KR. The relationship between mechanical and physiologica! energy estimates. Med Sci Sports Exerc 1985; 17: 317 - 325

${ }^{42}$ Woledge RC. Possible effects of fatigue on muscle efficiency. Acta Physiol Scand 1998; 162: 267-273

\section{Corresponding Author:}

\section{Pr J. Brisswalter}

Université Ergonomie Sportive et Performance

Université de Toulon-Var

Avenue de l'Université

BP 132

F-83957 La Garde cedex

France

Phone: $+33(494) 142613$

Fax: $\quad+33(494) 142278$

E-mail: brisswalter@univ-tln.fr 